\title{
Body after baby: a pilot survey of genital body image and sexual esteem following vaginal birth
}

\author{
This article was published in the following Dove Press journal: \\ International Journal of Women's Health \\ 13 April 2017 \\ Number of times this article has been viewed
}

\section{Ruth Zielinski' \\ Lisa Kane Low ${ }^{1-3}$ \\ Abigail R Smith ${ }^{4}$ \\ Janis M Miller ${ }^{1,3}$}

'Department of Health Behavior and Biological Sciences, School of Nursing, University of Michigan, Ann Arbor, MI, USA; ' 2 Department of Women's Studies, College of Literature, Science and the Arts, University of Michigan, Ann Arbor, MI, USA; ${ }^{3}$ Department of Obstetrics and Gynecology, University of Michigan, Ann Arbor, MI, USA; ${ }^{4}$ Arbor Research Collaborative for Health, Ann Arbor, MI, USA
Correspondence: Ruth Zielinski Department of Health Behavior and Biological Sciences, University of Michigan School of Nursing, 400 North Ingalls Street, Ann Arbor, MI 48109-5482, USA Tel +l 7346470324

Email ruthcnm@umich.edu
Objective: The aim of this study was to determine acceptability of the Vaginal Changes Sexual and Body Esteem (VSBE) scale for women post childbirth and explore the association between childbirth events and sexual/body esteem.

Design: This is a cross-sectional study within the Evaluating Maternal Recovery from Labor and Delivery study.

Setting: This study was conducted in a community setting.

Population: The study was conducted in women post first vaginal birth with birth events that posed risk factors for levator ani muscle tears.

Methods: Survey, magnetic resonance images of levator ani, and physical examination were the data collected 8 months postpartum. Birth variables were collected by hospital chart review. Descriptive analysis of VSBE response rates and distribution of responses was conducted. An exploratory analysis of the potential association of demographic, birth, clinical, and magnetic resonance image characteristics with VSBE scores was conducted.

Main outcome measures: The outcome measure used in this study is VSBE scale.

Results: The majority of participants (97\%) completed the scale, with responses to most questions skewed toward positive sexual/body esteem, with the exception of sexual enjoyment, where $38 \%$ indicated some interference due to genital changes. The scale showed high internal consistency (alpha $=0.93$ ). In the exploratory analysis of potential characteristics associated with VSBE, women with episiotomies had lower sexual/body esteem compared to those who did not (median VSBE scores 35 vs 42.5, $P=0.01$ ). Anal sphincter tear was not associated with sexual/body esteem $(P=0.78)$. Additional study is indicated to further explore observed trends toward the association of severe levator ani tear, maternal age at childbirth, and forceps with VSBE scores.

Conclusion: The VSBE is suitable for use to assess sexual/body esteem in women post childbirth. Most women in this sample did not indicate negative genital body image/sexual esteem. However, some indicated that the changes post birth negatively affected their sexual/body esteem, particularly those who had episiotomies.

Keywords: childbirth, pelvic floor disorders, episiotomy, genital cosmetic surgery, scale development, pelvic organ prolapse, Kegel muscle

\section{Introduction}

Childbirth is a time of dramatic change for women - physically, psychologically, and emotionally. Virtually every system of the body adapts during pregnancy to support and nourish the fetus. ${ }^{1}$ While necessary to fetal growth and development, some changes may be distressing to women. Some women anxiously await the birth of their baby so that they can "get their body back". ${ }^{2}$ However, many of the body changes such as weight gain and striae gravidarum (stretch marks) may take a significant amount 
of time to recover or may never resolve. Studies of body image during the perinatal period have focused primarily on pregnancy rather than the postpartum period. ${ }^{3}$ The few studies that include assessments of body image post childbirth suggest that many women experience dissatisfaction and have unrealistic expectations about regaining their prepregnant body. ${ }^{4}$

Moving from the general perception of body image to the specifics of genital body image is an area relevant to the postchildbirth phase, given the extensive changes that occur with childbirth, yet it is even less well understood. Qualitatively, some women express concerns about post-birth body changes to their genitals - specifically about their vaginas being too "loose", 5 a perception attributed to childbirth-related tears of the levator ani or "Kegel" muscle. ${ }^{6}$ Women's perceptions of negative changes to the vaginal area may be fueled by social media and websites depicting negative changes associated with childbirth that promote genital cosmetic surgery procedures such as vaginoplasty and labiaplasty as a solution. ${ }^{7}$ Specific genital changes associated with vaginal birth, such as episiotomy and anal sphincter lacerations, can cause pain with intercourse and delay the resumption of sexual activity. ${ }^{8}$ However, the relationship between genital changes associated with childbirth, body image, and sexual health has not been adequately explored either in the clinical environment or in the research environment.

The Vaginal Changes Sexual and Body Esteem (VSBE) was previously developed for women to evaluate their body using questions recognizing potential vaginal/rectal changes due to pelvic organ prolapse ${ }^{9}$ or potentially childbirth. The scale stems from the conceptual work of Taleporos and McCabe, ${ }^{10}$ who defined sexual esteem as a "positive regard for, and confidence in an individual's capacity to experience his or her sexuality in a satisfying and enjoyable way", and described body esteem as referring to one's self evaluation of their body. The survey, however, has not previously been used in a sample of postpartum women.

The overall purpose of this planned ancillary study was to begin assessing genital body image and sexual esteem in women post vaginal birth. Specifically, we sought, 1) to ascertain whether the VSBE is suitable for use and has acceptability in women post first vaginal birth, 2) to determine which women do or do not perceive changes to their vaginal/genital area, 3 ) for those who do perceive changes, to determine whether these changes are associated with negative body/sexual esteem, and 4) to explore whether demographic or birth variables, such as levator ani tear, episiotomy, and anal sphincter tear, influence body/sexual esteem changes post childbirth.

\section{Methods Study design}

We used a planned ancillary study approach, embedding a body/sexual esteem scale within a larger research project known as Evaluating Maternal Recovery from Labor and Delivery (EMRLD). EMRLD is an Institutional Review Board-approved (University of Michigan MED IRB HUM00051193) longitudinal cohort study following women recruited early post first birth. The sampling technique was purposeful for the parent project (EMRLD) to generate an enriched sample of women more likely to have levator ani tears. Risk factors included long length of second-stage labor ( $>150$ minutes), anal sphincter tear, instrumental delivery (vacuum or forceps), episiotomy, or age $>32$ years. ${ }^{11}$ Details of the sampling strategies from the parent project have been previously published ${ }^{12}$ as have main study outcomes. ${ }^{13}$

\section{Study sample and data collection time points}

In the parent longitudinal cohort study, data collection time points included early postpartum (on average, 7 weeks) and late postpartum (on average, 8 months). The VSBE scale, a sexual/ body esteem questionnaire, was administered only late postpartum to allow adequate time for healing and because more women would have resumed sexual activity at this time point. Written informed consent was obtained from each participant prior to collection of any study data. Figure 1 portrays the strobe diagram of the participant recruitment from the larger study.

\section{Instruments VSBE scale}

The VSBE was developed to evaluate body and sexual esteem in people experiencing vaginal/rectal changes and was initially piloted in women with pelvic organ prolapse. ${ }^{9}$ The VSBE includes ten items, each scored from 1 (strongly agree) to 5 (strongly disagree). The total score, formed by summing the responses to all ten questions, ranges from 10 to 50 . Lower scores (marked toward the scale end "strongly agree") indicate more negative genital body image.

For use in postpartum women, we included the option to check a box at the very beginning indicating "do not want to complete this questionnaire" in the VSBE. We recognize that the questions are of a sensitive nature and that women may want this choice. We also revised the VSBE to offer a response option of "no changes to the vaginal/rectal area" for each of the ten questions so that changes post childbirth were not presumed. The full questionnaire is provided as Supplementary material (Table S1), which shows post study minor wording revisions to questions 8 and 10. These questions 
originally used the phrase "a normal vaginal/rectal area", but we now recommend the revised "an unchanged vaginal/rectal area" to avoid a presumed idealized conceptualization for what would constitute "normal" women's genitals (refer to the "Discussion" section).

\section{Demographic and birth variables}

Demographic information included age, race, education, and annual income. Birth variables were obtained through medical chart review and included mode of birth, length of time in labor, maternal age, and infant size. Perineal outcomes were identified and categorized according to whether or not an episiotomy was performed and/or degree of perineal laceration sustained.

\section{Magnetic resonance imaging and clinical procedures} As a part of the parent study, musculoskeletal protocol magnetic resonance images (MRIs) of the pelvic structures were obtained. The radiologists measured and scored four sites of likely musculoskeletal injury related to childbirth. ${ }^{14}$ A score was created by combining the raw data for each side of the levator ani: " 0 " was none or subtle, " 1 " was $<50 \%$ loss unilateral, " 2 " was $\geq 50 \%$ unilateral or $<50 \%$ bilateral, and " 3 " was $\geq 50 \%$ bilateral muscle fiber loss. The MRI was obtained both early and late, with prior reported results showing that there was essentially no changes in the types or severity of the levator ani tear between the timepoints. ${ }^{13}$ The late postpartum clinical examination included the pelvic organ prolapse quantification (POP-Q) system, ${ }^{15}$ which has measurements within it that were potentially relevant to genital body image. For instance, measures of genital hiatus (measured in centimeters from the urethral meatus to the posterior midline hymen) and descent of the vaginal walls (measured in centimeters above or below the hymen) were made and included in this exploratory analysis.

\section{Statistical methods}

Demographic characteristics of participants are shown as mean, standard deviation, and range for continuous variables and frequencies and percentages for categorical variables. Birth and post-childbirth characteristics are described in the same manner. Women who utilized the response option of "no vaginal/rectal changes" for at least nine of the ten questions were considered to have perceived no childbirth-related changes, and their questionnaire was not scored. For women who responded on the 1-5 scale to at least eight questions, their VSBE score was calculated as the sum of the 10 items and the weighted summation was used to account for missing data or responses of no change. The VSBE scale was graphed using box plots for participants with and without episiotomies, anal sphincter tear, and levator ani tear by severity. Potential associations between the VSBE scale and birth variables, POP-Q, and levator ani tear were explored using Wilcoxon and Kruskal-Wallis tests for categorical variables and Spearman correlations for continuous variables. All analyses were completed using SAS 9.4 (SAS Institute, Cary, NC, USA).

\section{Results}

In this article, we report on all EMRLD participants with risk factors for levator ani tear who were asked to complete the VSBE at their late postpartum, $\sim 8$ months follow-up visit $(n=71)$. Figure 1 portrays the strobe diagram relevant to the VSBE. All participants were $>18$ years, primary English speakers, had a live, singleton birth, and were included in the study between June 2005 and March 2012. Responses to the ten VSBE questions are shown in a bar graph (Figure 2) with each bar representing the percentage of participants with a given response to each question. Overall, the sample averaged an age at childbirth of $\sim 30$ years and was predominately white and highly educated (Table 1). Sample birth characteristics showed relatively long length of second-stage labor and higher rates of perineal lacerations and anal sphincter tears on average, which is consistent with the recruitment criteria of the parent study. On MRI, 42\% exhibited some degree of levator ani tear.

In terms of evaluating questionnaire acceptability, of the 71 participants, only two $(2.8 \%)$ participants declined to complete the VSBE (both of them did complete the other study questionnaires). Of the two women who declined filling out the questionnaire, one showed no levator ani tear, while the other had a grade I tear. One woman's race was white, and the other was Asian. Overall, the demographics, birth variables, and POP-Q measurements were not strikingly different in the two women who declined filling out the questionnaire compared to the remaining 69 participants.

Of the 69 women who completed the VSBE scale, eleven $(16 \%)$ women chose the response option no vaginal/rectal changes on nine $(n=3)$ or ten $(n=8)$ questions. Of the remaining 58 women who responded indicating changes, 56 women responded to all ten questions, one woman skipped one question, and one woman responded no changes to vaginal/ rectal area for two questions.

The remainder of the analysis of the VSBE excluded the eleven women who chose the response option no 


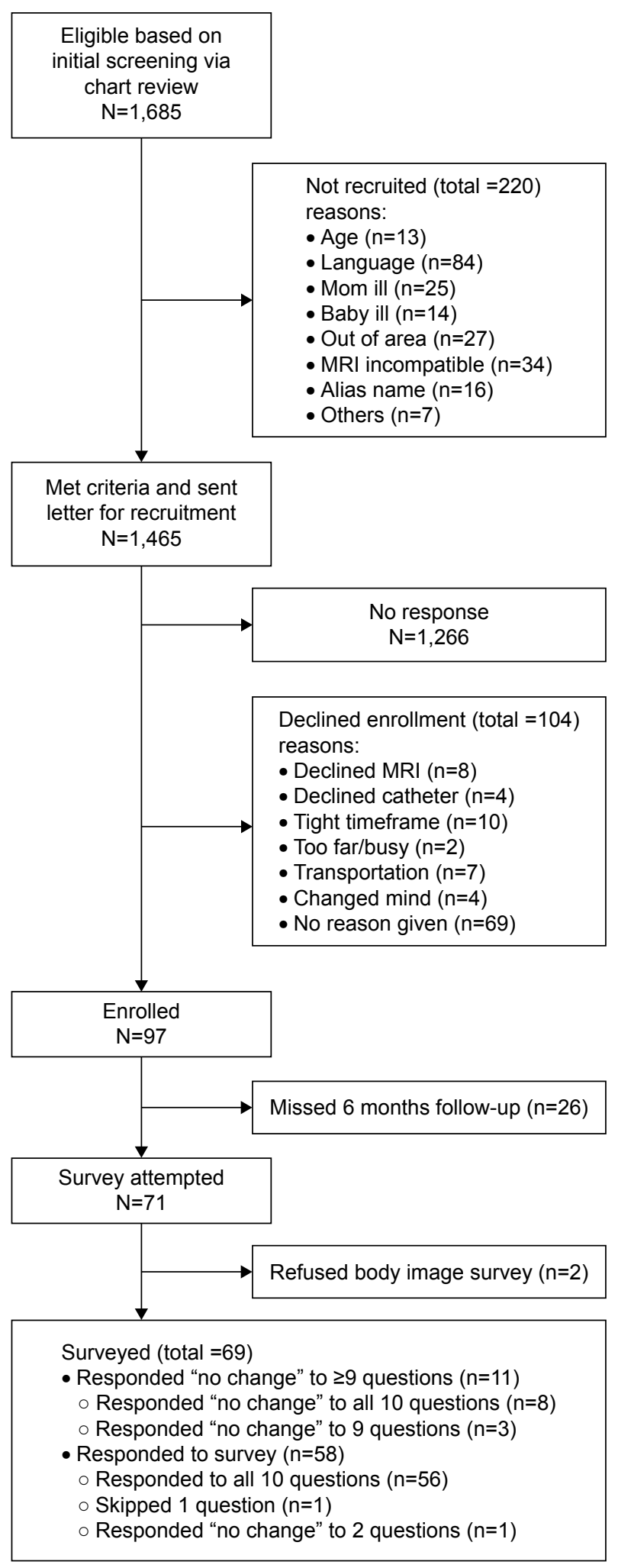

Figure I Strobe diagram.

Notes: Diagram showing recruitment into the EMRLD study, drop out late postpartum, and response to the survey. Note that recruitment differs from the Low et al ${ }^{12}$ study by $n=2$ due to the inclusion of two women who missed the early postpartum MRI in this report.

Abbreviations: EMRLD, Evaluating Maternal Recovery from Labor and Delivery; MRI, magnetic resonance image.
Table I Sample characteristics

\begin{tabular}{|c|c|c|}
\hline \multirow[t]{2}{*}{ Study variable } & \multicolumn{2}{|c|}{ Respondents ( $n=69)$} \\
\hline & Total & $\begin{array}{l}\text { Mean (SD) } \\
\text { or \% (N) }\end{array}$ \\
\hline \multicolumn{3}{|l|}{ Demographics } \\
\hline Maternal age (years) & 69 & $30.28(5.45)$ \\
\hline Race & 68 & \\
\hline Black/African American & & $3 \%(2)$ \\
\hline White & & $90 \%(6 I)$ \\
\hline Asian & & $3 \%(2)$ \\
\hline Other races & & $4 \%(3)$ \\
\hline Non-Hispanic/non-Latino & 68 & $100 \%(68)$ \\
\hline BMI $\left(\mathrm{kg} / \mathrm{m}^{2}\right)$ & 66 & \\
\hline$<18.5$ & & $6 \%(4)$ \\
\hline $18.5-24.9$ & & $45 \%(30)$ \\
\hline $25.0-29.9$ & & $29 \%(19)$ \\
\hline$>30.0$ & & $20 \%(13)$ \\
\hline Education & 67 & \\
\hline High school graduate or less & & $7 \%(5)$ \\
\hline Some college & & $19 \%(13)$ \\
\hline College/technical school graduate & & $27 \%(18)$ \\
\hline Graduate school & & $46 \%(3 I)$ \\
\hline Annual income & 66 & \\
\hline$<\$ 20,000$ & & $14 \%(9)$ \\
\hline$\$ 20,000-\$ 40,999$ & & $15 \%(10)$ \\
\hline$\$ 41,000-\$ 60,000$ & & $14 \%(9)$ \\
\hline$>\$ 60,000$ & & $58 \%(38)$ \\
\hline \multicolumn{3}{|l|}{ Birth variables } \\
\hline Infant's weight (g) & 68 & $3,421.01(509.62)$ \\
\hline Infant's head circumference $(\mathrm{cm})$ & 67 & $34.24(1.67)$ \\
\hline Anal tear & 69 & $33 \%(23)$ \\
\hline Episiotomy & 69 & $22 \%(15)$ \\
\hline Vacuum & 69 & $6 \%(4)$ \\
\hline Forceps & 69 & $4 \%(3)$ \\
\hline Second stage (minutes) & 68 & $164.7(132.04)$ \\
\hline LA tear severity & 68 & \\
\hline No LA tear & & $57 \%(39)$ \\
\hline Low severity LA tear & & $10 \%(7)$ \\
\hline Moderate severity LA tear & & $19 \%(13)$ \\
\hline High severity LA tear & & $13 \%(8)$ \\
\hline \multicolumn{3}{|l|}{ POP-Q } \\
\hline Anterior vaginal wall descent $(\mathrm{cm})$ & 66 & $-2.14(0.71)$ \\
\hline Cervix descent $(\mathrm{cm})$ & 65 & $-7.57(0.94)$ \\
\hline Genital hiatus $(\mathrm{cm})$ & 66 & $4.67(0.90)$ \\
\hline Urethra to anus $(\mathrm{cm})$ & 66 & $6.88(1.11)$ \\
\hline Posterior vaginal wall descent $(\mathrm{cm})$ & 66 & $-2.32(0.64)$ \\
\hline Total vaginal length $(\mathrm{cm})$ & 65 & $11.85(1.31)$ \\
\hline
\end{tabular}

Abbreviations: BMI, body mass index; LA, levator ani; POP-Q, pelvic organ prolapse quantification.

vaginal/rectal changes on nine or ten questions. Among these 58 participants who perceived change to their vaginal/rectal area post childbirth, the distribution of the responses to most VSBE questions was highly skewed toward the "strongly disagree" response, indicating positive body image (Figure 2). The first question regarding the changes in the vaginal/rectal 


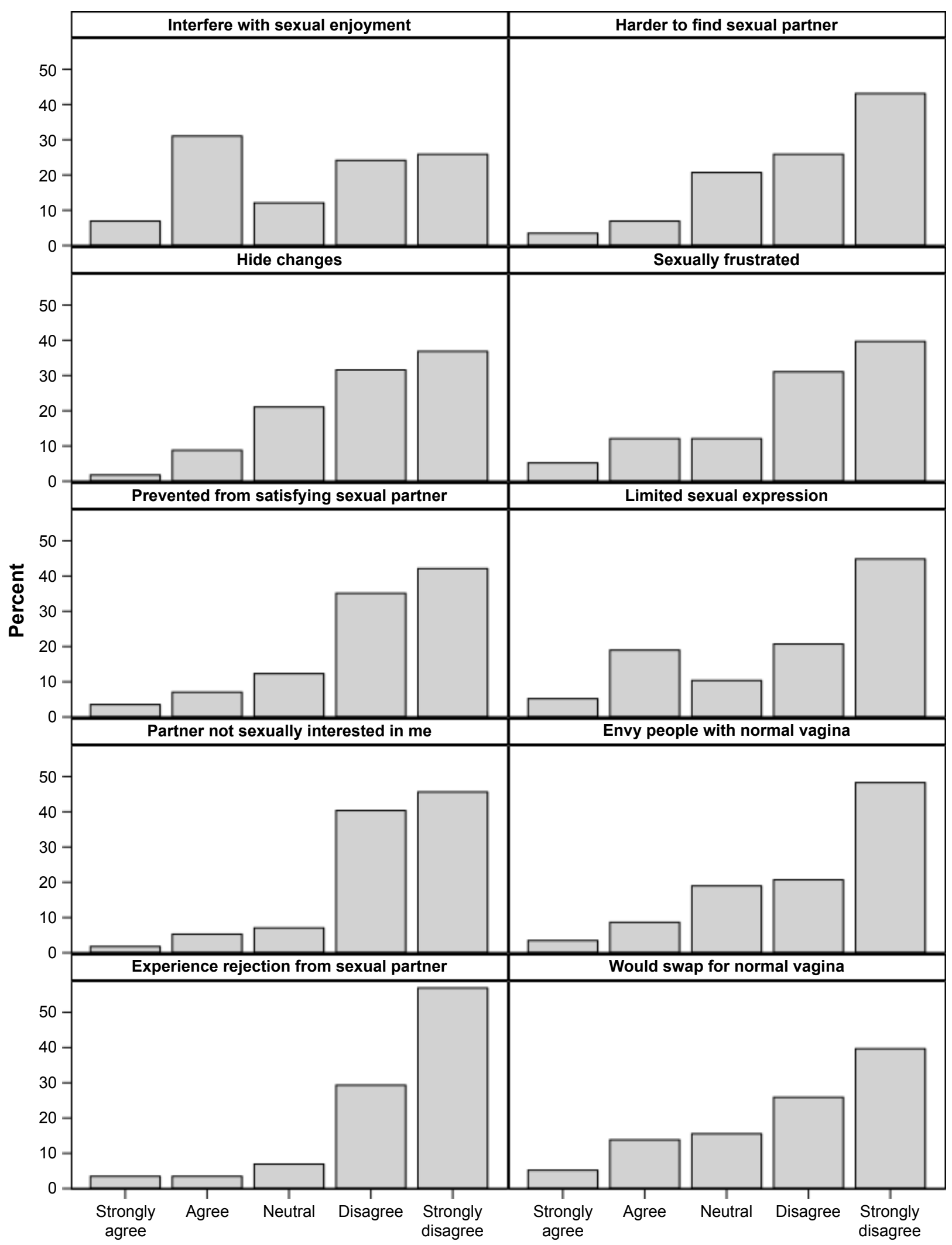

Figure 2 Distribution of responses to individual VSBE questions.

Notes: Vertical bar chart showing the percentage of women who gave each response for the ten VSBE questions. All responses are highly skewed toward the "strongly disagree" category, indicating positive genital body image with the exception of the question regarding interference with sexual enjoyment, which has a higher proportion that agreed with this statement compared to other questions.

Abbreviation: VSBE, Vaginal Changes Sexual and Body Esteem. 


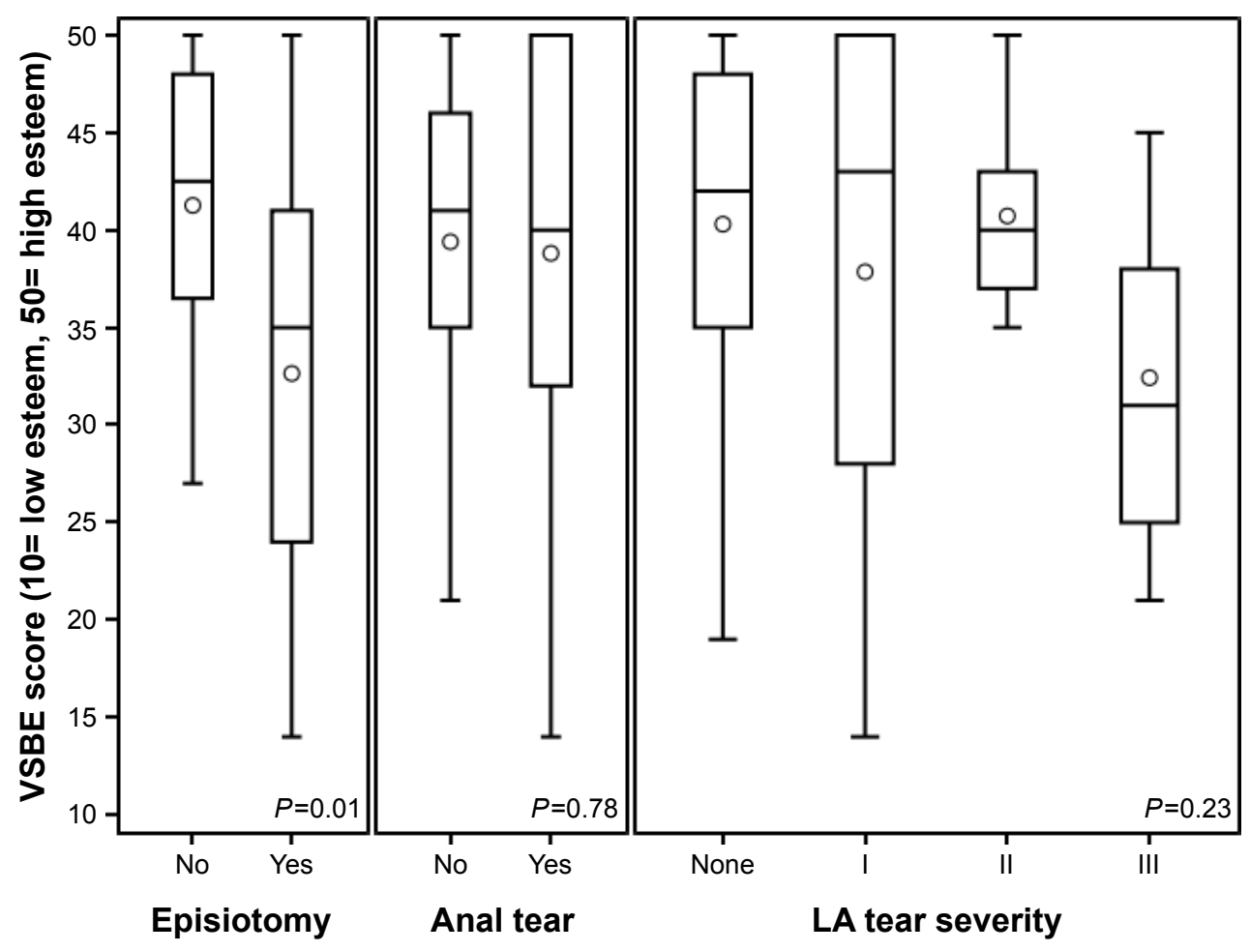

Figure 3 Distribution of VSBE scores by selected birth characteristics.

Notes: Box plots of VSBE score showing the mean (circle), median (line in box), and first and third quartiles (edges of box). Whiskers extend to I.5 times the interquartile range. Scores for women with episiotomies were significantly lower (worse) than scores for women who did not have episiotomies $(P=0.0 \mathrm{I})$, while there was no difference in scores for women with and without anal sphincter tears $(P=0.78)$. Women with the most severe LA tears (grade III) showed a trend toward lower (worse) scores, but this did not reach statistical significance $(P=0.23)$.

Abbreviations: LA, levator ani; VSBE, Vaginal Changes Sexual and Body Esteem.

area interfering with sexual enjoyment, however, had a higher proportion of "agree" responses (31\%) compared to the other questions $(<20 \%)$. The overall VSBE scale exhibited excellent internal consistency (reliability, alpha $=0.93$ ).

To further explore the data, total scores of the VSBE were tested for association with demographic, birth, MRI, and clinical measures. Results showed that participants who had episiotomies responded with lower scores (ie, more negative sexual and body esteem) compared to those who did not (median VSBE 35.0 vs 42.5, $P=0.01$; Figure 3). The three women with forceps delivery showed a trend toward lower VSBE scores with individual scores of 21, 29, and 38 , though, at this sample size, the significance is not reached $(P=0.07)$.

In addition, although not statistically significant, participants with grade III levator ani tears showed a trend toward lower VSBE scores compared to those with no tear or lower severity tears (Figure 3), which warrants further investigation. There was no association between the VSBE and race, education or annual income, or with infant size (weight or head circumference), length of second-stage labor, or any of the POP-Q measures. Maternal age showed a negative association with VSBE ( $r$ o $=-0.3, P=0.02$ ), indicating that older women tended to have lower scores (more negative sexual and body esteem); however, on further investigation, this was largely driven by a small number of older women $(\mathrm{n}=2$, women $>40$ years) and requires further investigation.

\section{Discussion}

As there are currently no valid/reliable tools to measure women's sexual/body esteem specific to the potential vaginal/ genital changes associated with childbirth, this preliminary investigation begins to fill this gap in the literature. Our findings demonstrate acceptability among participants and show that the VSBE is suitable for use in identifying those women whose scores point to major changes in perceived vaginal body image and self-esteem. These findings concur with the earlier testing of the VSBE in women with pelvic organ prolapse, which also showed high acceptability and demonstrated validity when scores were compared with qualitative comments during interviews regarding sexuality and body image. ${ }^{9}$ As expected, women with prolapse who were sexually active had lower VSBE scores, indicating more negative genital body image/sexual esteem than women who 
were not sexually active. ${ }^{9}$ One limitation of our current study is that we do not know which women were sexually active.

New findings of note are that a majority of the study participants (84\%) felt they had experienced vaginal/rectal changes associated with childbirth; however, these findings must be placed in context, since women were recruited who had more complex vaginal birth than the general population. In this sample, most of the women who perceived genital changes post childbirth exhibited positive vaginal sexual and self-esteem as evidenced by high VSBE scores. An exception was participants who underwent episiotomy at the time of birth. Women in this group on average had significantly lower scores on the VSBE scale, indicating that they perceived changes to their rectal/vaginal area that negatively impacted their sexual/body esteem. While these findings are in contrast to conventional understanding of episiotomy as resulting in a more esthetically appealing repair, ${ }^{16}$ they are consistent with prior evidence that episiotomy results in lower sexual functioning post childbirth. ${ }^{17}$ Although explanations are beyond the scope of this exploratory study, we can speculate that the known association of episiotomy with increased pain with intercourse after birth and more vaginal dryness ${ }^{17}$ may, in part, contribute to genital body image dissatisfaction.

Prior research study results indicate that those who sustain anal sphincter injuries are more likely to not be sexually active at a year post childbirth. ${ }^{18}$ However, for women in this study, sustaining anal sphincter tear (third or fourth degree laceration) did not result in lower body image or sexual esteem. Because the VSBE does not ask if the woman is sexually active, it is possible that at the time of survey data collection (on average, 8 months post birth), participants in this study who sustained anal sphincter trauma may not have resumed sexual activity and, therefore, these questions were not relevant to them. Alternatively, this may underscore the point that often it is the perception of changes that are more likely to cause dissatisfaction than objectively measurable physical changes in the genital area. This may also explain the trend toward lower scores on the VBSE scale for the three women who had a delivery by forceps.

While the association between levator ani injury and body image dissatisfaction has been speculated, in this sample, the severity levels of levator ani muscle tear did not significantly correlate with how participants felt about their genitals or their sexual esteem, although this may be in part related to sample size. Graphically, those with the most severe tears (bilateral tear) had lower scores on the VSBE, indicating worse sexual/ body esteem (Figure 3). A bilateral tear indicates that the muscle had detached on both sides of its attachment at the pubic bone, with resultant loss of a main support structure for the pelvic organs. Bilateral levator ani muscle tear has been described by others as causing increased genital hiatus size, or pelvic muscle "laxity". ${ }^{6}$ Levator ani tears have also been associated with pelvic organ prolapse that typically does not present until later in life. Pelvic organ prolapse has been shown to negatively influence genital body image and, subsequently, sexual health., ${ }^{9,19}$ Women in this study were, on average, 30 years old and 8 months post birth, which may explain the lack of association between levator ani injury and negative genital body image and the lack of externally visible prolapse for any women in the sample. Additionally, women would rarely know that they have a levator ani tear unless there were other associated symptoms that warranted evaluation by high-tech instruments, such as MRI. ${ }^{13}$

Two questions included in the original disabilities scale and modified for the VSBE refer to a normal vagina/rectum. There is wide variation in women's genitals, and upon reflection, these two items may result in an assumption of a more narrow definition of what is normal. The use of the term normal may also contribute to promote a conceptualization that idealizes what constitutes normal genitals. In the context of a cultural "norm" of desirability of a tighter vagina and trim, uniform labia that is widely portrayed in the media and cited by women in other studies, ${ }^{5,7}$ the decision was made to replace the potentially value laden term normal with "unchanged vagina/rectum" for future studies.

Limitations of the study include that participants were not asked specifically about their current sexual practices, partner status, or sexual orientation. However, the option of a "not applicable" response choice allowed some flexibility for the participants to answer the questionnaire in the manner most appropriate to their own situation. Prior research suggests that even at 1 year postpartum, not all women have resumed sexual activity, ${ }^{18}$ particularly if they have significant perineal trauma. ${ }^{18,20}$ Therefore, some participants in this study evaluated at approximately 8 months may not yet have resumed sexual activity. Participants in this research were primarily white and well-educated; testing the VSBE in a more diverse sample is warranted. The results reported here are an ancillary investigation of the VSBE in which the parent study recruited a sample of women with higher risk for having a levator ani tear during childbirth; thus, generalizability of findings is restricted. However, the enriched sampling of women with more complex birth histories allowed for greater variance in birth variables and, hence, exploration for associations with the VSBE scores. 
The small sample size in this study precluded factor analysis; further research with larger samples is needed to determine if the VSBE demonstrates factors similar to those identified by Taleporos and $\mathrm{McCabe}^{10}$ in the original sexual and body esteem scale used in people with disabilities. While this study suggests that women undergoing forceps-assisted birth may experience more sexual/body esteem dissatisfaction, larger numbers are needed to confirm these findings.

\section{Conclusion}

While it is well established that body image dissatisfaction is associated with a decline in sexual health for women, there is limited understanding of women's experience of physical changes after childbirth and potential for negative sexual/body esteem specific to the genital area. Messages from social media and advertisements for genital cosmetic surgery portray negative vaginal and labial changes occurring with birth that subsequently interfere with women's sexual pleasure. ${ }^{7}$ The results of this investigation show high acceptability in postpartum women for filling out the VSBE and provide preliminary evidence that while a majority of women do not perceive bothersome changes to their vaginal/ genital area post childbirth, some women do. This pilot study suggests that episiotomy has more negative impact on genital body image scores than childbirth-related anal sphincter tears or partial levator ani tear. The VSBE performed well as a measure of women's sexual/body esteem specific to the genital area post childbirth. With further studies, determination of a cutoff point that would indicate a score considered to be concerning or outside of the norm regarding genital sexual/body image/sexual esteem may be identified. Future use of the scale as a screening tool in the clinical setting should be explored, and its use in studies of childbirth may offer increased understanding of genital area changes postpartum and the impact of those changes on those who experience them.

\section{Acknowledgments}

The EMRLD study is grant-supported by the National Institutes of Health (NIH) through the Office for Research on Women's Health Specialized Center of Research (SCOR) on Sex and Gender Factors Affecting Women's Health and National Institute on Child and Human Development (grant \#P50 HD044406 002) and the National Institute on Child and Human Development (grant \#R21 HD049818). The content of this article is solely the responsibility of the authors and does not necessarily represent the official views of the NIH or its institutes. The sponsor had no involvement in study design, collection, analysis, and interpretation of data, writing of the report, or decision to submit the article for publication.

\section{Author contributions}

RZ, LKL, and JMM conceived and designed the study. RZ, LKL, and JMM acquired the data. RZ, LKL, ARS, and JMM analyzed and interpreted the data. RZ, LKL, ARS, and JMM drafted and critically revised the article. All authors contributed toward data analysis, drafting and revising the paper and agree to be accountable for all aspects of the work.

\section{Disclosure}

The authors report no conflicts of interest in this work.

\section{References}

1. Gabbe S. Obstetrics: Normal and Problem Pregnancies. 6th ed. Philadelphia, PA: Elsevier Saunders; 2012.

2. Brown A, Rance J, Warren L. Body image concerns during pregnancy are associated with a shorter breast feeding duration. Midwifery. 2015;31(1):80-89.

3. Watson B, Fuller-Tyszkiewicz M, Broadbent J, Skouteris H. The meaning of body image experiences during the perinatal period: a systematic review of the qualitative literature. Body Image. 2015;14:102-113.

4. Clark A, Skouteris H, Wertheim E, Paxton SJ, Milgrom J. My baby body: a qualitative insight into women's body-related experiences and mood during pregnancy and the postpartum. J Reprod Infant Psychol. 2009; 27(4):330-345.

5. Olsson A, Lundqvist M, Faxelid E, Nissen E. Women's thoughts about sexual life after childbirth: focus group discussions with women after childbirth. Scand J Caring Sci. 2005;19(4):381-387.

6. Thibault-Gagnon S, Yusuf S, Langer S, et al. Do women notice the impact of childbirth-related levator trauma on pelvic floor and sexual function? Results of an observational ultrasound study. Int Urogynecol J. 2014; 25(10):1389-1398.

7. Braun V. Female genital cosmetic surgery: a critical review of current knowledge and contemporary debates. $J$ Womens Health (Larchmt). 2010;19(7):1393-1407.

8. McDonald EA, Brown SJ. Does method of birth make a difference to when women resume sex after childbirth? BJOG. 2013;120(7): 823-830.

9. Zielinski R, Low LK, Tumbarello J, Miller JM. Body image and sexuality in women with pelvic organ prolapse. Urol Nurs. 2009;29(4): 239-246.

10. Taleporos G, McCabe M. Development and validation of the physical disability sexual and body esteem scale. Sex Disabil. 2002;20(3): 159-176.

11. Kearney R, Miller J, Ashton-Miller J, DeLancey JO. Obstetric factors associated with levator ani muscle injury after vaginal birth. Obstet Gynecol. 2006;107(1):144-149.

12. Low LK, Zielinski R, Tao Y, Galecki A, Brandon CJ, Miller JM. Predicting birth-related levator ani tear severity in primiparous women: evaluating maternal recovery from labor and delivery (EMRLD Study). Open J Obstet Gynecol. 2014;4(6):266-278.

13. Miller JM, Low LK, Zielinski R, Smith AR, DeLancey JO, Brandon C. Evaluating maternal recovery from labor and delivery: bone and levator ani injuries. Am J Obstet Gynecol. 2015;213(2):188.e1-188.e11.

14. Brandon C, Jacobson JA, Low LK, Park L, DeLancey J, Miller J. Pubic bone injuries in primiparous women: magnetic resonance imaging in detection and differential diagnosis of structural injury. Ultrasound Obstet Gynecol. 2012;39(4):444-451. 
15. Bump R, Mattiasson A, Bo K, et al. The standardization of terminology of female pelvic organ prolapse and pelvic floor dysfunction. Am J Obstet Gynecol. 1996;175(1):10-17.

16. Richardson AC, Lyon JB, Graham EE, Williams NL. Decreasing postpartum sexual abstinence time. Am J Obstet Gynecol. 1976;126(4): 416-417.

17. Ejegård H, Ryding E, Sjogren B. Sexuality after delivery with episiotomy: a long-term follow-up. Gynecol Obstet Invest. 2008;66(1):1-7.

18. van Brummen HJ, Bruinse $\mathrm{HW}$, van de Pol G, Heintz AP, van der Vaart CH. Which factors determine the sexual function 1 year after childbirth? BJOG. 2006;113(8):914-918.
19. Zielinski R, Miller JM, Low LK, Sampselle C, DeLancey J. The relationship between pelvic organ prolapse, genital body image, and sexual health. Neurourol Urodyn. 2012;31(7):1145-1148.

20. Radestad I, Olsson A, Nissen E, Rubertsson C. Tears in the vagina, perineum, sphincter ani, and rectum and first sexual intercourse after childbirth: a nationwide follow-up. Birth. 2008;35(2):98-106. 


\section{Supplementary material}

Table SI Vaginal Changes Sexual and Body Esteem Scale

\begin{tabular}{|c|c|c|c|c|c|c|}
\hline & $\begin{array}{l}\text { Strongly } \\
\text { agree }\end{array}$ & Agree & Neutral & Disagree & $\begin{array}{l}\text { Strongly } \\
\text { disagree }\end{array}$ & $\begin{array}{l}\text { No vaginal/rectal } \\
\text { changes }\end{array}$ \\
\hline $\begin{array}{l}\text { I. I feel that the changes to my vaginal/rectal area may cause } \\
\text { interference with my sexual enjoyment. }\end{array}$ & I & 2 & 3 & 4 & 5 & $\mathrm{n} / \mathrm{a}$ \\
\hline $\begin{array}{l}\text { 2. If I were looking for a sexual partner it may be harder to find one } \\
\text { because I have these kinds of changes to my vaginal/rectal area. }\end{array}$ & I & 2 & 3 & 4 & 5 & $\mathrm{n} / \mathrm{a}$ \\
\hline $\begin{array}{l}\text { 3. I would like to hide the changes to my vaginal/rectal area as much } \\
\text { as possible. }\end{array}$ & I & 2 & 3 & 4 & 5 & $\mathrm{n} / \mathrm{a}$ \\
\hline $\begin{array}{l}\text { 4. I feel sexually frustrated because of the changes to my vaginal/ } \\
\text { rectal area. }\end{array}$ & I & 2 & 3 & 4 & 5 & $\mathrm{n} / \mathrm{a}$ \\
\hline $\begin{array}{l}\text { 5. I feel that the changes to my vaginal/rectal area are likely to } \\
\text { prevent me from satisfying a sexual partner. }\end{array}$ & 1 & 2 & 3 & 4 & 5 & $\mathrm{n} / \mathrm{a}$ \\
\hline $\begin{array}{l}\text { 6. I feel my sexual expression may be limited by the changes to my } \\
\text { vaginal/rectal area. }\end{array}$ & I & 2 & 3 & 4 & 5 & $\mathrm{n} / \mathrm{a}$ \\
\hline $\begin{array}{l}\text { 7. I feel that a sexual partner might not be as sexually interested } \\
\text { in me because of the changes to my vaginal/rectal area. }\end{array}$ & I & 2 & 3 & 4 & 5 & $\mathrm{n} / \mathrm{a}$ \\
\hline 8. I envy people with an unchanged vagina/rectum. & 1 & 2 & 3 & 4 & 5 & $\mathrm{n} / \mathrm{a}$ \\
\hline $\begin{array}{l}\text { 9. I believe that I may experience rejection from a sexual partner } \\
\text { because of the changes to my vaginal/rectal area. }\end{array}$ & I & 2 & 3 & 4 & 5 & $\mathrm{n} / \mathrm{a}$ \\
\hline 10. I would do a swap for an unchanged vagina/rectum if I could. & I & 2 & 3 & 4 & 5 & $\mathrm{n} / \mathrm{a}$ \\
\hline
\end{tabular}

Abbreviation: n/a, not applicable.

\section{Publish your work in this journal}

The International Journal of Women's Health is an international, peerreviewed open-access journal publishing original research, reports, editorials, reviews and commentaries on all aspects of women's healthcare including gynecology, obstetrics, and breast cancer. The manuscript management system is completely online and includes a very quick and fair peer-review system, which is all easy to use. Visit http://www.dovepress.com/testimonials.php to read real quotes from published authors. 